\title{
Correction to: Lattice Defects Generated by Cyclic Thermomechanical Loading of Superelastic NiTi Wire
}

\author{
Ondřej Tyc ${ }^{1,3} \cdot$ Luděk Heller ${ }^{1,2} \cdot$ Petr Šittner ${ }^{1,2}$
}

Published online: 5 April 2021

(C) ASM International 2021

\section{Correction to:}

\section{Shape Memory and Superelasticity} https://doi.org/10.1007/s40830-021-00315-4

The original article has been corrected.

Publisher's Note Springer Nature remains neutral with regard to jurisdictional claims in published maps and institutional affiliations.

This erratum is to correct the figure captions which were split into two columns. The captions for Figs. 2, 4, and 10-15 will be corrected to match the other captions.

The original article can be found online at https:// doi.org/10.1007/s40830-021-00315-4.

\footnotetext{
Petr ̌̌ittner sittner@fzu.cz

1 Institute of Physics of the CAS, Na Slovance, 1992/2, 18221 Prague, Czechia

2 Nuclear Physics Institute of the CAS, Husinec - Rez 130, 25068 Rez, Czechia

3 Faculty of Nuclear Sciences and Physical Engineering, CTU Prague, Prague 2, Czechia
} 